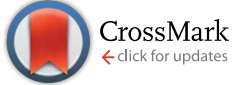

Cite this: RSC Adv., 2015, 5, 40785

Received 2nd February 2015

Accepted 14th April 2015

DOI: $10.1039 / c 5 r a 02035 b$

www.rsc.org/advances

\section{Synthesis and characterization of ferric tannate as a novel porous adsorptive-catalyst for nitrogen removal from wastewater}

\begin{abstract}
Ruina Zhang, Lin Li and Junxin Liu*
Ferric tannate has unique adsorption capacities for $\mathrm{NH}_{4}{ }^{-}-\mathrm{N}$ and $\mathrm{NO}_{2}{ }^{-}-\mathrm{N}$ simultaneously. So far, no normative method is available for synthesizing ferric tannate. In this work, an optimized method for synthesizing ferric tannate by using tannic acid and ferric chloride is established under the conditions of room temperature and neutral $\mathrm{pH}$. The optimal molar ratio of tannic acid and ferric chloride were determined to be in the range of $1: 20$ to $1: 25$ based on the yield and stability of the ferric tannate composite. Scanning electron microscopy, the Brunauer-Emmett-Teller method, X-ray diffraction, and Fourier transform infrared spectrometry were used to characterize the ferric tannate composite. The results showed that the ferric tannate has a rough and porous surface, a large surface area, and an amorphous structure. Experiments of $\mathrm{NH}_{4}{ }^{+}-\mathrm{N}$ and $\mathrm{NO}_{2}{ }^{-}-\mathrm{N}$ adsorption reflected that the ferric tannate composite has a unique capacity for adsorption-catalyzed conversion of $\mathrm{NH}_{4}{ }^{+}-\mathrm{N}$ and $\mathrm{NO}_{2}{ }^{-}-\mathrm{N}$ to $\mathrm{N}_{2}$. When the mass ratios of ferric tannate/ $\mathrm{NH}_{4}{ }^{+}-\mathrm{N}$ and ferric tannate $/ \mathrm{NO}_{2}{ }^{-}-\mathrm{N}$ were both 200 , the removal of $\mathrm{NH}_{4}{ }^{+}-\mathrm{N}$ and $\mathrm{NO}_{2}{ }^{-}-\mathrm{N}$ was $98.1 \%$ and $96.2 \%$, respectively, after 3.0 hours of reaction. The conversion rate of $\mathrm{N}_{2}$ increased to $87.1 \%$. Therefore, ferric tannate can be used as a potential material for removing nitrogen from wastewater in the future.
\end{abstract}

\section{Introduction}

Nitrogen in wastewater is acknowledged as one of the critical causes of severe eutrophication of receiving water bodies. In order to satisfy the strict sewage discharge standards, many technologies for wastewater nitrogen removal have been extensively developed, such as biological nitrogen removal, chemical oxidation, adsorption, and ion exchange. Currently, biological nitrogen removal through the combination of aerobic nitrification and anoxic denitrification is widely applied in wastewater treatment plants. However, this approach requires a large amount of oxygen for nitrification, and a sufficient amount of organic substrates to maintain denitrification, which results in high energy consumption. ${ }^{1}$ Another biotechnology, anaerobic ammonium oxidation (Anammox), is recognized as a promising alternative for nitrogen removal. In the Anammox process, $\mathrm{NO}_{2}{ }^{-}-\mathrm{N}$ is converted to nitrogen gas $\left(\mathrm{N}_{2}\right)$ with $\mathrm{NH}_{4}{ }^{+}-\mathrm{N}$ as the electron donor; this process consumes less energy and does not require additional carbon substrate as the electron donor. ${ }^{2}$ However, Anammox bacteria exhibit an extremely slow growth rate, limiting its wide practical application. ${ }^{3,4}$

The chemical approach for nitrogen removal gives a greater reaction rate and a higher removal efficiency, but this approach

Research Center for Eco-Environmental Sciences, Chinese Academy of Sciences, 18 Shuangqing Road, Haidian District, Beijing 100085, China. E-mail: jxliu@rcees.ac. cn; Fax: +8610 62849133; Tel: +861062849133 requires additional oxidants or reductants, thereby causing high costs and complicating operational procedures., Adsorption and ion exchange approaches, such as using activated carbon and zeolites, can quickly remove $\mathrm{NH}_{4}{ }^{+}-\mathrm{N}, \mathrm{NO}_{2}-\mathrm{N}$, and $\mathrm{NO}_{3}-\mathrm{N}$ from wastewater. However, the adsorbent and ion exchange resins must be regenerated after the saturation of adsorbed nitrogen, and the regenerated solution needs further disposal, leading to higher environmental and economical costs. ${ }^{7-11}$ Thus, adsorption would be an attractive alternative approach for wastewater nitrogen removal if the adsorbent resin can be regenerated in situ.

Theoretically, the redox reaction for $\mathrm{N}_{2}$ production occurs between $\mathrm{NH}_{4}{ }^{+}-\mathrm{N}$ and $\mathrm{NO}_{2}-\mathrm{N}$ based on their standard redox potential, ${ }^{12}$ but the reaction rate depends on the reaction conditions significantly. Chemical kinetics indicate that the reaction rate can be accelerated through increasing the concentrations of reactants. ${ }^{13}$ Adsorption can transform reactants from liquids into solids, causing the reactants to be concentrated on the surface of adsorbents. ${ }^{14}$ A very recent patent implied that the presence of ferric tannate (a kind of magnetic nanoparticle) is capable of accelerating this reaction at room temperature. ${ }^{15}$ Furthermore, a highly cross-linked network of ferric tannate was found to exhibit a rough and porous surface, ${ }^{\mathbf{1 6}}$ capable of absorbing both negative and cationic ions due to its ferric ions and negative oxygen ions. In addition, $\mathrm{N}_{2} \mathrm{H}_{4}$ and $\mathrm{NH}_{2} \mathrm{OH}$ are intermediate products in the reaction of $\mathrm{NO}_{2}-\mathrm{N}$ and $\mathrm{NH}_{4}{ }^{+}-\mathrm{N},{ }^{17-19}$ while ferric ions can convert 
$\mathrm{N}_{2} \mathrm{H}_{4}$ and $\mathrm{NH}_{2} \mathrm{OH}$ to $\mathrm{N}_{2} \cdot{ }^{20-22}$ Thus, ferric tannate may be used as a novel solution for nitrogen removal. Even though many previous studies have illustrated the development and applications of magnetic nanoparticles in nitrogen removal, ${ }^{23-25}$ no literature has clearly demonstrated that these magnetic nanoparticles, including ferric tannate, could efficiently eliminate $\mathrm{NH}_{4}{ }^{+}-\mathrm{N}$ and $\mathrm{NO}_{2}{ }^{-}-\mathrm{N}$ simultaneously, as well as accelerate the redox reaction between these two substances. Additionally, no approach has been developed to date for synthesizing ferric tannate that can be efficiently used in wastewater treatment.

Therefore, this study aims to develop an optimized approach for synthesizing ferric tannate, which can accelerate the reaction between $\mathrm{NH}_{4}{ }^{+} \mathrm{N}$ and $\mathrm{NO}_{2}{ }^{-} \mathrm{N}$. Tannic acid and ferric chloride were used as the raw materials to synthesize ferric tannate under the combined conditions of room temperature and neutral pH. Moreover, Fourier transform infrared spectrometry (FTIR) and the Brunauer-Emmett-Teller (BET) method were used to analyze the functional groups and surface morphology of the produced ferric tannate. This study also investigated the potential nitrogen removal performance of ferric tannate in wastewater treatment. The objective of this study is to synthesize a material that can accelerate the reaction between $\mathrm{NO}_{2}{ }^{-}-\mathrm{N}$ and $\mathrm{NH}_{4}{ }^{+}-\mathrm{N}$.

\section{Materials and methods}

\section{Materials}

Tannic acid and ferric chloride $\left(\mathrm{FeCl}_{3}\right)$ were used to synthesize ferric tannate. Tannic acid $\left(\mathrm{C}_{76} \mathrm{H}_{52} \mathrm{O}_{46}\right.$, molar mass: $1701.18 \mathrm{~g}$ $\mathrm{mol}^{-1}$ ) was purchased from Sigma-Aldrich Co., USA, with a pure grade of $\geq 99.5 \%$. $\mathrm{FeCl}_{3}, \mathrm{NH}_{4} \mathrm{Cl}$, and $\mathrm{NaNO}_{2}$ were purchased from Sinopharm Chemical Reagent Co., China, with a pure grade of $\geq 99 \%$. $\mathrm{NaHCO}_{3}$ was purchased from Tianjin Jinke Fine Chemical Research Institute, China, with a pure grade of $\geq 99.5 \%$. The solutions of tannic acid, $\mathrm{FeCl}_{3}$, and $\mathrm{NaHCO}_{3}$ were prepared with distilled water at concentrations of $0.1,1$, and $0.65 \mathrm{~mol} \mathrm{~L}^{-1}$, respectively.

\section{Synthesis of ferric tannate}

Tannic acid is an abundant polyphenolic compound. Its orthophenolic hydroxyl structure can cause complexation reactions with ferrous and ferric ions, which form a hybrid with metalorganic frameworks. The chemical structures of tannic acid and ferric tannate are shown in Fig. 1. ${ }^{26,27}$ In view of the complexity of the chemical structure of tannic acid, six molar ratios of tannic acid and $\mathrm{FeCl}_{3}(1: 10,1: 15,1: 20,1: 25,1: 30$, and $1: 40)$ were chosen to investigate the influence of the varying proportions on ferric tannate yield. The synthesis of ferric tannate was performed in a conical flask with a volume of 150 $\mathrm{mL}$. An amount of $10 \mathrm{~mL}$ of $0.1 \mathrm{~mol} \mathrm{~L}^{-1}$ tannic acid solution was mixed with various volumes of $1 \mathrm{~mol} \mathrm{~L}^{-1} \mathrm{FeCl}_{3}$ solution. The $\mathrm{pH}$ of the mixture was adjusted to 7 by using $0.65 \mathrm{~mol} \mathrm{~L}^{-1} \mathrm{NaHCO}_{3}$ solution. The reaction products were separated via sedimentation, and the resultant precipitate was washed with deionized water four times, centrifuged (3000 rpm, $2 \mathrm{~min}$ ), and dried in a freezer dryer at $-50^{\circ} \mathrm{C}$.

\section{Characterization of ferric tannate}

The ferric tannate yield $\left(y_{\mathrm{e}}\right)$ was calculated using the following equation (eqn (1)):

$$
y_{\mathrm{e}}=\frac{m_{\mathrm{ft}}}{\left(m_{\mathrm{t}}+m_{\mathrm{fe}}\right)} \times 100 \%
$$

where $m_{\mathrm{ft}}$ is the mass of the ferric tannate (mg), and $m_{\mathrm{t}}$ and $m_{\mathrm{fe}}$ are the masses of tannic acid and ferric chloride (mg), respectively.

To determine the stability of the ferric tannate yield, $0.2 \mathrm{~g}$ of the ferric tannate composition, which was prepared with different ratios as mentioned earlier, was placed into six shake flasks. Then, each shake flask was charged with $200 \mathrm{~mL}$ of deionized water. After $1 \mathrm{~h}$ of continuous stirring, the mixture in each shake flask was filtered through a $0.45 \mu \mathrm{m}$ pore size filter. The filtrate was measured with a UV-vis spectrophotometer (UV1700, Hitachi Co., Japan) at a $200 \mathrm{~nm}$ to $500 \mathrm{~nm}$ wavelength.

Field emission scanning electron microscopy (FE-SEM), which was coupled with an energy dispersive X-ray spectroscopy (EDS) detector (SU-8020, Hitachi Co., Japan), was employed to observe the surface physical morphology and major elements of ferric tannate.

An automatic micropore and mesopore analyzer (ASAP 2020 HD88, USA) was operated to analyze the specific surface area and pore size distribution of ferric tannate. Moreover, the specific surface area and pore size distribution of the ferric tannate were determined with a $\mathrm{N}_{2}$ adsorption isotherm at $77 \mathrm{~K}$ by using a Micromeritics ASAP 2010 accelerated surface area analyzer and the BET method. ${ }^{28}$

Fourier transform infrared spectrometry (FTIR, Tensor 27, Germany) was applied to measure the functional groups of tannic acid and ferric tannate with the potassium bromide pellet method in the range of $400 \mathrm{~cm}^{-1}$ to $4000 \mathrm{~cm}^{-1} .^{29}$

X-ray diffraction (XRD, X'Pert PRO MPD, PANalytical, Holland) was used to analyze the purity and crystallinity of ferric tannate, ferric chloride, and tannic acid with $\mathrm{Cu}-\mathrm{K} \alpha$ radiation $(\lambda=0.015418 \mathrm{~nm})$ in the $2 \theta$ range of $10^{\circ}$ to $80^{\circ}$. The XRD data were collected in a scan mode with a step length of $0.5^{\circ}$ with a scanning rate of $6^{\circ} \mathrm{min}^{-1}$. The accelerating voltage and the applied current were $45 \mathrm{kV}$ and $45 \mathrm{~mA}$, respectively.

\section{Determination of the nitrogen removal performance}

Several batch tests were conducted in stoppered conical flasks to estimate the nitrogen removal performance of the synthesized ferric tannate. Stock solutions were prepared by dissolving $\mathrm{NH}_{4} \mathrm{Cl}$ and/or $\mathrm{NaNO}_{2}$ in deionized water. Each time, $0.1 \mathrm{~g}$ ferric tannate and $50 \mathrm{~mL}$ stock solution were mixed in a flask, which was then shaken with a shaker at $200 \mathrm{rpm}$ at room temperature. In the procedure of nitrogen removal by using ferric tannate, the $\mathrm{pH}$ was 7 , which was adjusted with $\mathrm{HCl}$ or $\mathrm{NaHCO}_{3} \cdot{ }^{30}$

In the adsorption isotherm studies, stock solutions with different initial concentrations of $\mathrm{NH}_{4}{ }^{+}-\mathrm{N}$ or $\mathrm{NO}_{2}{ }^{-}-\mathrm{N}$ were added into $100 \mathrm{~mL}$ conical flasks, and the equilibrium time was set to $2 \mathrm{~h}$. The samples were separated via filtration.

In the experiments, the concentrations of both $\mathrm{NH}_{4}{ }^{+}-\mathrm{N}$ and $\mathrm{NO}_{2}{ }^{-}-\mathrm{N}$ in the reaction solutions were $50 \mathrm{mg} \mathrm{L}^{-1} .100 \mathrm{~mL}$ stock 


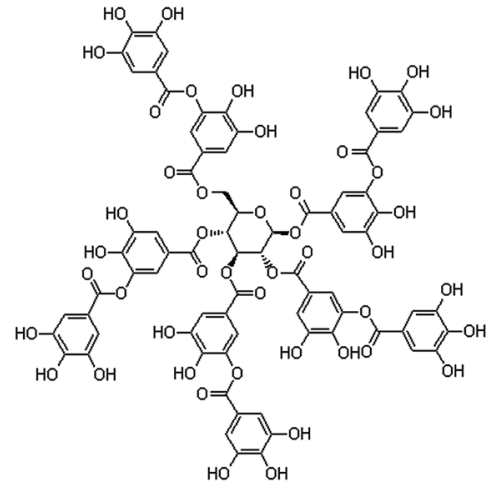

$\boldsymbol{a}$

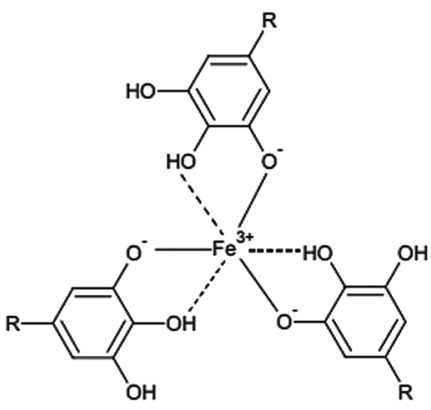

b

Fig. 1 Schematic diagram of the chemical structures of (a) tannic acid and (b) ferric tannate.

Table 1 Yield of ferric tannate from different ratios of tannic acid and $\mathrm{FeCl}_{3}$

Ratio (tannic acid/FeCl 3 ) $1: 10 \quad 1: 15 \quad 1: 20 \quad 1: 25 \quad 1: 30 \quad 1: 40$ Yield (\%)

\section{$\begin{array}{llllll}71.3 & 75.4 & 78.4 & 79.2 & 82.6 & 78.4\end{array}$}

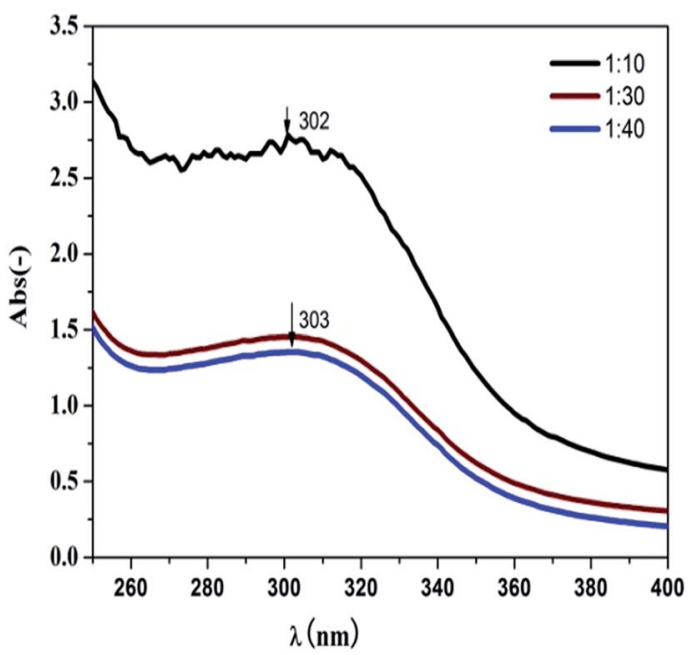

Fig. 2 UV-visible absorbance spectra of the soak water of the ferric tannate composite.

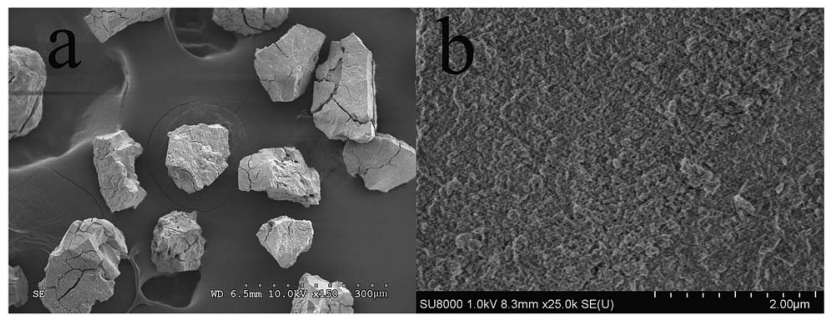

Fig. 3 SEM of 1 : 20 tannic acid/FeCl3: (a) ferric tannate composition and (b) its microstructure.

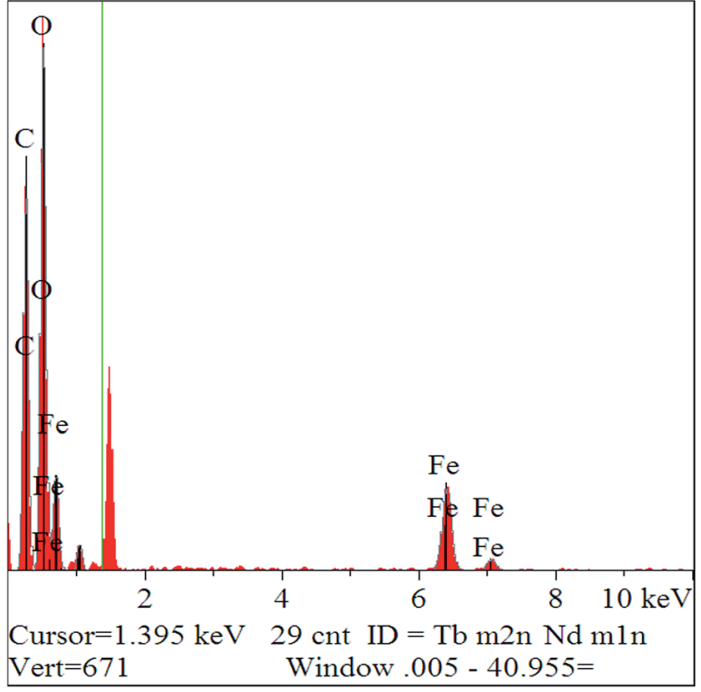

Fig. 4 SEM-EDS spectrum of the ferric tannate composite $(1: 20$ tannic acid/ $/ \mathrm{FeCl}_{3}$ ).

solution and $1.0 \mathrm{~g}$ ferric tannate were added into a $150 \mathrm{~mL}$ stoppered conical flask. Then, the flask was shaken at $200 \mathrm{rpm}$ for $3.0 \mathrm{~h}$ at room temperature, and $500 \mu \mathrm{L}$ water samples and 50 $\mu \mathrm{L}$ gas samples were collected every $20 \mathrm{~min}$. In the study, the data of $\mathrm{NH}_{4}{ }^{+}$and $\mathrm{NO}_{2}{ }^{-}$adsorption on the ferric tannate at room temperature were obtained through three groups of parallel tests.

The concentrations of $\mathrm{NH}_{4}{ }^{+} \mathrm{N}$ and $\mathrm{NO}_{2}{ }^{-} \mathrm{N}$ were measured according to standard methods. ${ }^{31}$ The Agilent $6890 \mathrm{~N}$ Gas Chromatograph equipped with a TCD was used to analyse the content of $\mathrm{N}_{2}$.

The adsorption amount of $\mathrm{NH}_{4}{ }^{+}-\mathrm{N}$ or $\mathrm{NO}_{2}{ }^{-}-\mathrm{N}$ on the ferric tannate at equilibrium, $q_{\mathrm{e}}\left(\mathrm{mg}_{\mathrm{N}} \mathrm{g}^{-1}\right)$, was calculated with the following equations (eqn (2) and (3)):

$$
q_{\mathrm{e}}=\frac{\left(C_{\mathrm{i}}-C_{\mathrm{e}}\right) V}{m}
$$




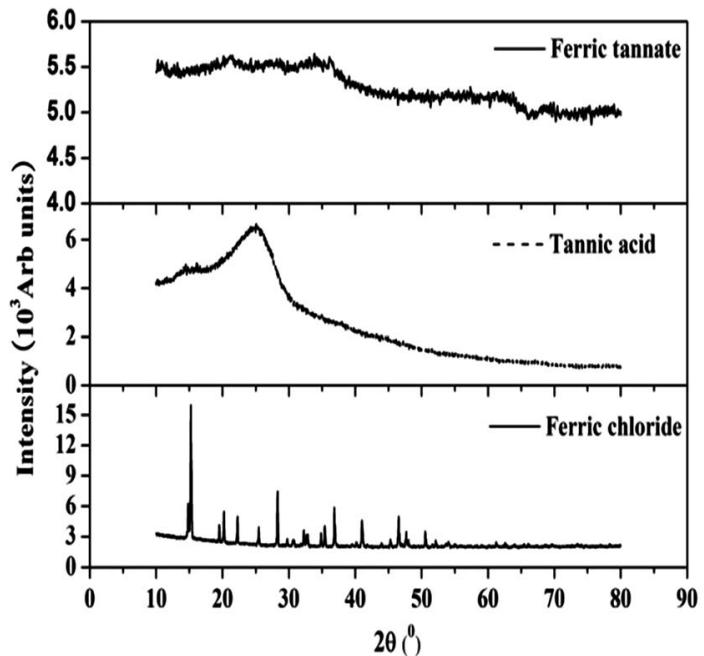

Fig. 5 XRD spectra of the tannic acid, $\mathrm{FeCl}_{3}$ and ferric tannate composite $\left(1: 20\right.$ tannic acid/ $\left./ \mathrm{FeCl}_{3}\right)$.

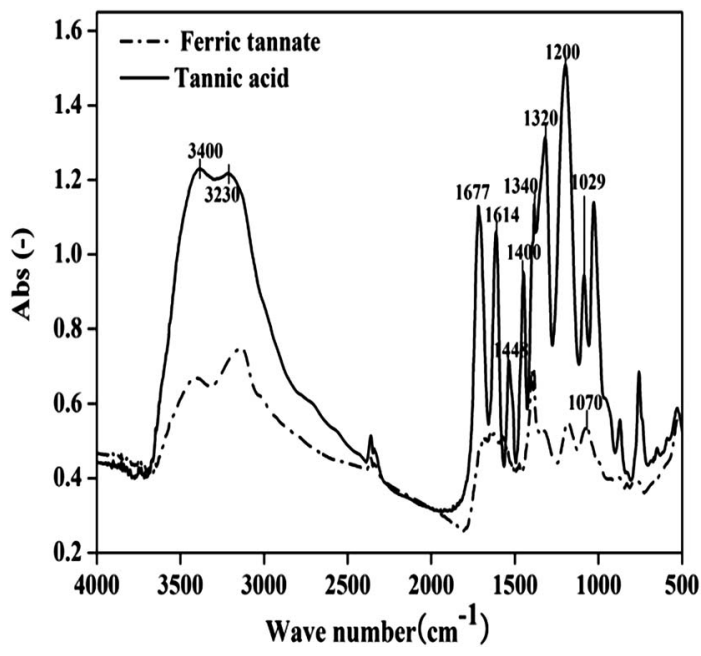

Fig. 6 FTIR spectra of tannic acid and ferric tannate (1: 20 tannic acid/ $\left.\mathrm{FeCl}_{3}\right)$.

$$
\text { Removal }=\frac{\left(C_{\mathrm{i}}-C_{\mathrm{e}}\right)}{C_{\mathrm{i}}} \times 100 \%
$$

where $q_{\mathrm{e}}$ is the equilibrium amount of adsorption on the adsorbent surface $\left(\mathrm{mg}_{\mathrm{N}} \mathrm{g}^{-1}\right)$, and $C_{\mathrm{i}}$ and $C_{\mathrm{e}}$ are the initial and equilibrium concentrations of $\mathrm{NH}_{4}{ }^{+} \mathrm{N}^{-}$or $\mathrm{NO}_{2}{ }^{-} \mathrm{N}\left(\mathrm{mg}_{\mathrm{N}} \mathrm{L}^{-1}\right)$ in the solution, respectively. $V$ is the volume of the solution (L), and $m$ is the mass of the ferric tannate $(\mathrm{g})$.

The Langmuir adsorption equation and the Freundlich adsorption equation can be linearised according to the equation in ref. 32.

Due to the inherent bias resulting from linearisation of the isotherm model, error analysis was employed as a criterion for the fitting quality. This statistical analysis is based on the sum of the squares of the differences between the experimental and the Langmuir model and Freundlich model calculated data. The

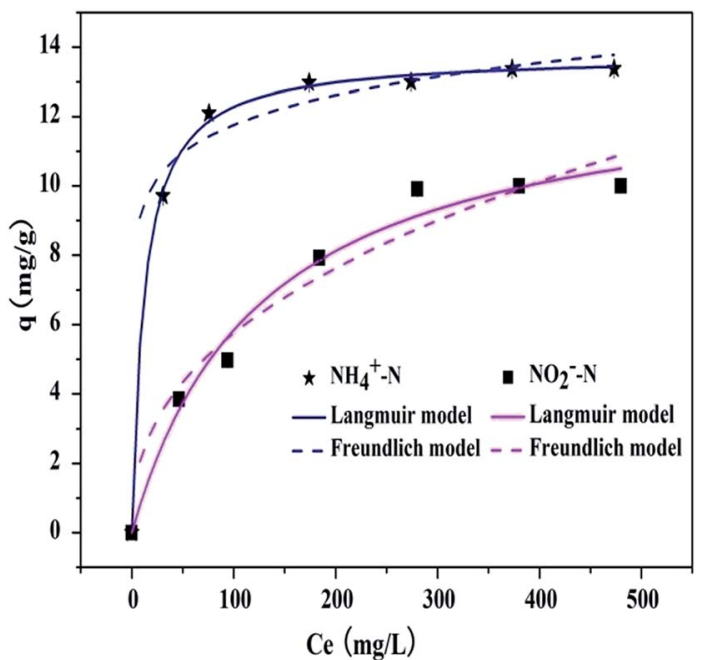

Fig. 7 Adsorption isotherms of $\mathrm{NH}_{4}{ }^{+}-\mathrm{N}$ and $\mathrm{NO}_{2}{ }^{-}-\mathrm{N}$ on ferric tannate.

Table 2 Langmuir and Freundlich isotherm parameters for $\mathrm{NH}_{4}{ }^{+}-\mathrm{N}$ and $\mathrm{NO}_{2}{ }^{-}-\mathrm{N}$ adsorption by ferric tannate

\begin{tabular}{llllllll}
\hline & \multicolumn{3}{c}{ Langmuir parameters } & & & \multicolumn{2}{l}{ Freundlich parameters } \\
\cline { 2 - 3 } & $K_{\mathrm{L}}\left(\mathrm{L} \mathrm{mg}^{-1}\right)$ & $\begin{array}{l}q_{\mathrm{m}} \\
\left(\mathrm{mg} \mathrm{g}^{-1}\right)\end{array}$ & $R^{2}$ & & $\begin{array}{l}K_{\mathrm{F}}[(\mathrm{mg} \\
\left.\left.\mathrm{g}^{-1}\right) /\left(\mathrm{mg} \mathrm{L}^{-1}\right)^{n}\right]\end{array}$ & $n$ & $R^{2}$ \\
\hline $\mathrm{NH}_{4}{ }^{+}-\mathrm{N}$ & 0.079 & 13.9 & 0.990 & 7.06 & 0.109 & 0.860 \\
$\mathrm{NO}_{2}{ }^{-}-\mathrm{N}$ & 0.009 & 10.2 & 0.957 & 2.84 & 4.53 & 0.952
\end{tabular}

error was calculated using the following equations (eqn (4) and $(5))$ :

Relative error $=\frac{\sum_{i=1}^{n}\left|\frac{q_{i}-q_{\mathrm{sim}}}{q_{i}}\right|}{n} \times 100 \%$

Standard deviation $=\sqrt{\frac{1}{n} \sum_{i=1}^{n}\left(\left|\frac{q_{i}-q_{\mathrm{sim}}}{q_{i}}\right|-\frac{1}{n} \sum_{i=1}^{n}\left|\frac{q_{i}-q_{\mathrm{sim}}}{q_{i}}\right|\right)^{2}}$

where $q_{i}$ is the equilibrium capacity of the adsorbent obtained from the experiment $\left(\mathrm{mg} \mathrm{g}^{-1}\right)$, and $q_{\mathrm{sim}}$ is the simulated adsorption capacity which is calculated with the Langmuir equation and the Freundlich equation $\left(\mathrm{mg} \mathrm{g}^{-1}\right)$.

A low value of the relative error or standard deviation indicates that the experimental data fit better to the value from the model. In order to confirm the best-fit isotherms and kinetic models for the adsorption system, there is a need to analyse the data set using the Nash-Sutcliffe efficiency (NSE). ${ }^{33,34}$ As a dimensionless goodness-of-fit indicator, the values of the NSE could be widely used and a potentially reliable statistic for assessing the goodness-of-fit of isotherm adsorption models. NSE $=1$ indicated a perfect fit, $0.75 \leq$ NSE $\leq 0.9$ suggested a good fit, and $0.65 \leq$ NSE $\leq 0.749$ suggested an acceptable fit. NSE is calculated as follows (eqn (6)): 
Table 3 The data of error estimation and the NSE

\begin{tabular}{|c|c|c|c|c|c|c|c|c|}
\hline & \multicolumn{4}{|c|}{ Error estimation (\%) } & \multicolumn{4}{|l|}{ NSE } \\
\hline Test1 & $1.51 \pm 1.24$ & $1.46 \pm 1.44$ & $3.50 \pm 2.28$ & $2.94 \pm 2.07$ & 0.972 & 0.994 & 0.854 & 0.992 \\
\hline Test2 & $1.58 \pm 0.901$ & $1.67 \pm 1.19$ & $3.51 \pm 2.32$ & $2.74 \pm 2.29$ & 0.976 & 0.996 & 0.849 & 0.991 \\
\hline
\end{tabular}

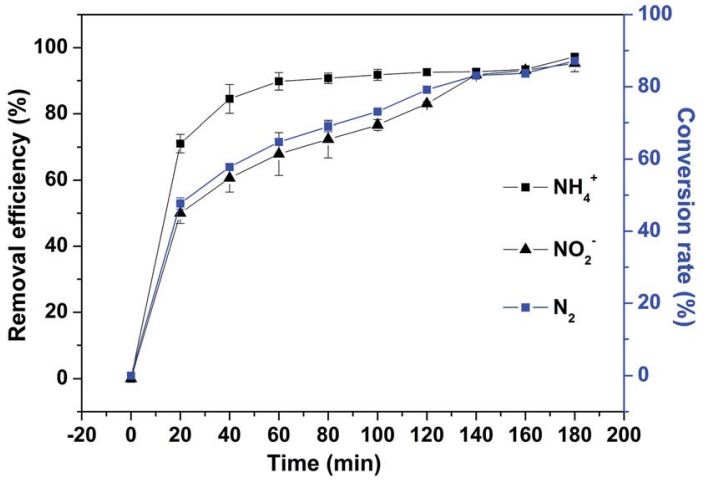

Fig. 8 The removal of $\mathrm{NH}_{4}{ }^{+}-\mathrm{N}$ and $\mathrm{NO}_{2}{ }^{-}-\mathrm{N}$ and the conversion rate of $\mathrm{N}_{2}$ with the addition of ferric tannate.

$$
\mathrm{NSE}=1-\frac{\sum_{i=1}^{n}\left(q_{i}-q_{\mathrm{sim}}\right)^{2}}{\sum_{i=1}^{n}\left(q_{i}-\bar{q}\right)^{2}}
$$

where $q_{i}$ is the equilibrium capacity of the adsorbent obtained from the experiment $\left(\mathrm{mg} \mathrm{g}^{-1}\right), q_{\text {sim }}$ is the simulated adsorption capacity $\left(\mathrm{mg} \mathrm{g}^{-1}\right)$, and $\bar{q}$ is the average adsorption capacity $\left(\mathrm{mg} \mathrm{g}^{-1}\right)$.

\section{Synthesis of ferric tannate}

As expected, the reaction of tannic acid with $\mathrm{FeCl}_{3}$ resulted in the formation of an abundant precipitate of ferric tannate. Table 1 presents a summary of the results of the ferric tannate yield from the six proportions of tannic acid and $\mathrm{FeCl}_{3}$, which showed an obvious response between the ratio of tannic acid and $\mathrm{FeCl}_{3}$ and the ferric tannate yield. Increasing the proportion of tannic acid to $\mathrm{FeCl}_{3}$ from $1: 10$ to $1: 30$ resulted in the gradual increase of ferric tannate yields. The highest yield, $82.6 \%$, appeared in the case of the $1: 30$ ratio. Moreover, the ferric tannate yields are nearly equal in the cases of the $1: 20$, $1: 25$, and $1: 40$ ratios.

The stability of the ferric tannate composition in liquid will be highly important to apply it to nitrogen removal from wastewater. Therefore, the dissolution of the ferric tannate compositions in water was determined. The UV-visible absorbance spectra of the soak water of the ferric tannate compositions are shown in Fig. 2. The results showed that nothing could be dissolved in the cases of the $1: 15,1: 20$, and $1: 25$ ratios, but an absorption peak appeared at $302 \mathrm{~nm}$ in the case of the $1: 10$ ratio, and at $303 \mathrm{~nm}$ in the cases of the $1: 30$ and $1: 40$ ratios, which indicated that some substrates were dissolved into the water.

The preceding results indicated that the molar ratio of tannic acid to ferric ions was responsible for the formation of the ferric tannate complex. With strong reducibility, the phenolic hydroxyl groups in tannic acid can reduce $\mathrm{Fe}^{3+}$ to $\mathrm{Fe}^{2+} \cdot{ }^{35-37}$ In the case of the $1: 10$ ratio, the excess tannic acid can produce a dissolved ferrous tannate, with an absorption peak appearing at $302 \mathrm{~nm} .{ }^{38}$ In the cases of the $1: 30$ and $1: 40$ ratios, the ferric ion was in excess, which could lead to the formation of $\mathrm{Fe}(\mathrm{OH})_{3}$. Therefore, the absorption peak at $303 \mathrm{~nm}$ is probably from the ferric ion dissolution. ${ }^{39}$ Therefore, based on the yield and stability of the ferric tannate compositions, the optimal molar ratio of tannic acid and $\mathrm{FeCl}_{3}$ to synthesize ferric tannate is between $1: 20$ and $1: 25$.

\section{Characterization of ferric tannate}

According to the results of the preceding experiment, the synthesized sample in the case of the $1: 20$ ratio was selected to characterize the ferric tannate composite. FE-SEM images of the ferric tannate composite are illustrated in Fig. 3. The ferric tannate composite had a rough and porous surface structure. The adsorption isotherms of $\mathrm{N}_{2}$ on the ferric tannate composite were used to deduce the surface characteristics. The results showed that the BET surface area, pore volume, and average pore diameter were $97 \mathrm{~m}^{2} \mathrm{~g}^{-1}, 0.073 \mathrm{~cm}^{3} \mathrm{~g}^{-1}$, and $66.58 \mathrm{~nm}$, respectively. In general, a large surface area and pore diameter can increase the adsorption capacity of the material. ${ }^{40,41}$

The SEM-EDS spectrum of the ferric tannate composite is shown in Fig. 4. The composite mainly consists of $\mathrm{C}$, O, and Fe elements, and the percentage content of $\mathrm{C}, \mathrm{O}$, and $\mathrm{Fe}$ in the ferric tannate composite are $23.06 \%, 46.83 \%$, and $29.91 \%$, respectively. However, the ratio of $\mathrm{C}$ to $\mathrm{O}$ from the SEM-EDS spectrum is anomalous compared with the chemical formula of tannic acid $\left(\mathrm{C}_{76} \mathrm{H}_{52} \mathrm{O}_{46}\right)$. A possible explanation is that ferric ions partially undergo a hydrolysis reaction at neutral $\mathrm{pH}$, which leads to an increase of $\mathrm{O}$ in the ferric tannate composite. ${ }^{35,42,43}$ However, this finding should be verified with further research.

The XRD patterns of the tannic acid, $\mathrm{FeCl}_{3}$, and ferric tannate composite are shown in Fig. 5. XRD data indicate that $\mathrm{FeCl}_{3}$ has many diffraction peaks because of its crystalline structure ${ }^{44}$ The diffraction peaks of the tannic acid and ferric 
tannate composite appear in the $2 \theta=20^{\circ}$ to $30^{\circ}$ range, which demonstrates that they have an amorphous structure.

The FTIR spectra of the tannic acid and ferric tannate composite are illustrated in Fig. 6. Two broad adsorption bands in the $3600 \mathrm{~cm}^{-1}$ to $3100 \mathrm{~cm}^{-1}$ range indicating the presence of a phenolic hydroxyl group were observed, and the band at 1320 $\mathrm{cm}^{-1}$ exhibits a characteristic bending vibration of $\mathrm{O}-\mathrm{C}$ in a phenolic hydroxyl group. The sharp band at $1400 \mathrm{~cm}^{-1}$ in the spectrum of the ferric tannate composite is very pronounced, which can be ascribed to the adsorption peak of a $\mathrm{C}=\mathrm{O}$ vibration of benzoic acid. This phenomenon can be explained by the chelation and redox reaction of $\mathrm{Fe}^{3+}$ with the phenolic hydroxyl group, which results in the coexistence of $\mathrm{Fe}^{3+}$ and $\mathrm{Fe}^{2+}$ in ferric tannate. ${ }^{27,35}$ The interaction between $\mathrm{Fe}^{3+}$ and the phenolic hydroxyl group has an effect on the O-C bond stretching vibration, in which the band is shifted from $1320 \mathrm{~cm}^{-1}$ in the spectrum of the tannic acid to $1338 \mathrm{~cm}^{-1}$ in the spectrum of the ferric tannate composite. ${ }^{45-48}$ During the combination process of $\mathrm{Fe}^{3+}$ with the phenolic hydroxyl group, an oxygen anion was formed.

\section{Evaluation of the nitrogen removal performance of the ferric tannate composite}

Some batch tests for adsorbing $\mathrm{NH}_{4}{ }^{+}-\mathrm{N}$ and $\mathrm{NO}_{2}{ }^{-}-\mathrm{N}$ were conducted separately to estimate the nitrogen removal performance of the synthesized ferric tannate. The data of $\mathrm{NH}_{4}{ }^{+}-\mathrm{N}$ and $\mathrm{NO}_{2}{ }^{-}-\mathrm{N}$ adsorption on the ferric tannate composites, with only $\mathrm{NH}_{4}{ }^{+}-\mathrm{N}$ or $\mathrm{NO}_{2}{ }^{-}-\mathrm{N}$ in the solution, are shown in Fig. 7. The Langmuir and Freundlich models are usually used to describe the equilibrium isotherm data. The results from linear plots of these isotherms of $\mathrm{NH}_{4}{ }^{+}-\mathrm{N}$ and $\mathrm{NO}_{2}{ }^{-}-\mathrm{N}$ on the ferric tannate composites are listed in Table 2. Compared with the correlation coefficient value of the linear plot of the Freundlich isotherm, that of the Langmuir model was in better agreement with the observed data $\left(R^{2}=0.990\right.$ for $\mathrm{NH}_{4}{ }^{+}$-N adsorption and $R^{2}=0.957$ for $\mathrm{NO}_{2}{ }^{-} \mathrm{-N}$ adsorption). The maximum adsorption capacities of $\mathrm{NH}_{4}{ }^{+}-\mathrm{N}$ and $\mathrm{NO}_{2}{ }^{-}-\mathrm{N}$ calculated from the Langmuir equations were $13.6 \mathrm{mg} \mathrm{g}^{-1}$ and $10.2 \mathrm{mg} \mathrm{g}^{-1}$ at room temperature, respectively. The results indicated that the adsorption capacity of ferric tannate toward $\mathrm{NH}_{4}{ }^{+} \mathrm{N}$ was better than that toward $\mathrm{NO}_{2}{ }^{-}-\mathrm{N}$.

In the study, the values of the NSE (Table 3) indicated that the Langmuir models of $\mathrm{NH}_{4}{ }^{+}-\mathrm{N}_{\text {and }} \mathrm{NO}_{2}{ }^{-}-\mathrm{N}$ can be considered to be very good $(0.9 \leq \mathrm{NSE} \leq 1)$. The Freundlich models of $\mathrm{NH}_{4}{ }^{+}-\mathrm{N}$ and $\mathrm{NO}_{2}{ }^{-}-\mathrm{N}$ can be considered to be good $(0.8 \leq \mathrm{NSE} \leq$ $0.9)$ and very good $(0.9 \leq \mathrm{NSE} \leq 1)$, respectively.

The adsorption performances of ferric tannate toward $\mathrm{NH}_{4}{ }^{+}$ $\mathrm{N}$ and $\mathrm{NO}_{2}{ }^{-}-\mathrm{N}$ were different and varied significantly with time. Fig. 8 shows the adsorptive behaviors for $\mathrm{NH}_{4}{ }^{+} \mathrm{N}$ and/or $\mathrm{NO}_{2}{ }^{-}-\mathrm{N}$ on ferric tannate. The concentrations of $\mathrm{NH}_{4}{ }^{+}-\mathrm{N}$ and $\mathrm{NO}_{2}{ }^{-}-\mathrm{N}$ decreased with time, while the production of $\mathrm{N}_{2}$ increased over the same time (Fig. 8). When the mass ratios of ferric tannate/ $\mathrm{NH}_{4}{ }^{+}-\mathrm{N}$ and ferric tannate $/ \mathrm{NO}_{2}{ }^{-}-\mathrm{N}$ were both 200 , the removal efficiencies of $\mathrm{NH}_{4}{ }^{+} \mathrm{N}$ and $\mathrm{NO}_{2}{ }^{-} \mathrm{-}$ were $98.1 \%$ and $96.2 \%$, respectively, after 3.0 hours of reaction. The conversion rate of $\mathrm{N}_{2}$ increased to $87.1 \%$. The results showed that after the addition of ferric tannate, the removal of $\mathrm{NH}_{4}{ }^{+}-\mathrm{N}$ and $\mathrm{NO}_{2}{ }^{-}-\mathrm{N}$ increased obviously with $\mathrm{N}_{2}$ production increasing simultaneously, which indicated that ferric tannate would be beneficial for the reaction between $\mathrm{NH}_{4}{ }^{+}-\mathrm{N}$ and $\mathrm{NO}_{2}{ }^{-}-\mathrm{N}$, and lead to greater $\mathrm{N}_{2}$ generation. These results indicated that the ferric tannate had a unique capacity to adsorb anions and cations simultaneously, and an adsorption-catalyzed reaction occurred on the ferric tannate with the adsorption of $\mathrm{NH}_{4}{ }^{+}-\mathrm{N}$ and $\mathrm{NO}_{2}{ }^{-}$$\mathrm{N}$. The adsorption-catalyzed reaction between $\mathrm{NH}_{4}{ }^{+}-\mathrm{N}$ and $\mathrm{NO}_{2}{ }^{-}-\mathrm{N}$ could refresh the adsorption sites of ferric tannate, and the continuous adsorption of $\mathrm{NH}_{4}{ }^{+} \mathrm{N}$ and $\mathrm{NO}_{2}{ }^{-}-\mathrm{N}$ on the ferric tannate could be promoted. Thus, the removal amount of $\mathrm{NH}_{4}{ }^{+}$$\mathrm{N}$ and $\mathrm{NO}_{2}{ }^{-}-\mathrm{N}$ was enhanced. Therefore, the ferric tannate may be used as a promising material to remove nitrogen from wastewater in the future.

For practical use, the dosage of ferric tannate will be adjusted with the concentrations of $\mathrm{NH}_{4}{ }^{+}-\mathrm{N}$ and $\mathrm{NO}_{2}{ }^{-}-\mathrm{N}$ in the wastewater, for the purpose of increasing the amounts of $\mathrm{NH}_{4}{ }^{+}$$\mathrm{N}$ and $\mathrm{NO}_{2}{ }^{-}-\mathrm{N}$ converted to $\mathrm{N}_{2}$.

\section{Conclusions}

A novel method to synthesize porous ferric tannate composites was demonstrated by using tannic acid and ferric chloride under the conditions of room temperature and neutral $\mathrm{pH}$. According to the yield and stability of the ferric tannate composite, the optimal molar ratio of tannic acid and $\mathrm{FeCl}_{3}$ is between 1:20 and 1:25. Combined with the SEM and BET characterization, the characteristics of a porous surface and a large surface area of the ferric tannate composite were confirmed. XRD analysis confirmed that the ferric tannate composite has an amorphous structure. The adsorption test results indicated that the adsorption isotherm of $\mathrm{NH}_{4}{ }^{+} \mathrm{N}$ and $\mathrm{NO}_{2}{ }^{-}-\mathrm{N}$ on the ferric tannate composite agrees well with that obtained from the Langmuir model. Moreover, the maximum adsorption capacities of $\mathrm{NH}_{4}{ }^{+}-\mathrm{N}$ and $\mathrm{NO}_{2}{ }^{-}-\mathrm{N}$ calculated from the Langmuir equations were $13.6 \mathrm{mg} \mathrm{g}^{-1}$ and $10.2 \mathrm{mg} \mathrm{g}^{-1}$ at room temperature, respectively. Furthermore, ferric tannate has a unique capacity to adsorb $\mathrm{NH}_{4}{ }^{+} \mathrm{N}$ and $\mathrm{NO}_{2}{ }^{-}-\mathrm{N}$ simultaneously. In addition, an adsorption-catalyzed reaction can occur on the ferric tannate with the adsorption of $\mathrm{NH}_{4}{ }^{+}-\mathrm{N}$ and $\mathrm{NO}_{2}{ }^{-}-\mathrm{N}$, which enhances the removal efficiency of $\mathrm{NH}_{4}{ }^{+}-\mathrm{N}$ and $\mathrm{NO}_{2}{ }^{-}-\mathrm{N}$. When the mass ratios of ferric tannate/ $\mathrm{NH}_{4}{ }^{+}-\mathrm{N}$ and ferric tannate $/ \mathrm{NO}_{2}{ }^{-}-\mathrm{N}$ were both 200 , the removal efficiencies of $\mathrm{NH}_{4}{ }^{+}-\mathrm{N}$ and $\mathrm{NO}_{2}{ }^{-}-\mathrm{N}$ were $98.1 \%$ and $96.2 \%$, respectively, after 3.0 hours of reaction. The conversion rate of $\mathrm{N}_{2}$ increased to $87.1 \%$. Therefore, ferric tannate may be used as a promising material to remove nitrogen from wastewater in the future.

\section{Acknowledgements}

This study was financially supported by the National Science Foundation of China (no. 51138009 and 51208495).

\section{References}

1 A. Dey, Environ. Eng. Sci., 2010, 27, 757-765. 
2 B. Kartal, J. G. Kuenen and M. C. M. van Loosdrecht, Science, 2010, 328, 702-703.

3 M. Strous, J. J. Heijnen, J. G. Kuenen and M. S. M. Jetten, Appl. Microbiol. Biotechnol., 1998, 50, 589-596.

4 K. Isaka, Y. Date, T. Sumino, S. Yoshie and S. Tsuneda, Appl. Microbiol. Biotechnol., 2006, 70, 47-52.

5 I. Ihara, K. Umetsu, K. Kanamura and T. Watanabe, Bioresour. Technol., 2006, 97, 1360-1364.

6 Y. H. Liou, S. L. Lo, C. J. Lin, W. H. Kuan and S. C. Weng, J. Hazard. Mater., 2005, 127, 102-110.

7 G. D. Ji, Y. Zhou and J. J. Tong, Environ. Eng. Sci., 2010, 27, 871-878.

8 P. A. Terry, Environ. Eng. Sci., 2009, 26, 691-696.

9 S. Annouar, M. Mountadar, A. Soufiane, A. Elmidaoui and M. A. M. Sahli, Desalination, 2004, 165, 437.

10 S. Leakovic, I. Mijatovic, S. Cerjan-Stefanovic and E. Hodzic, Water Res., 2000, 34, 185-190.

11 H. Zheng, L. Han, H. Ma, Y. Zheng, H. Zhang, D. Liu and

S. Liang, J. Hazard. Mater., 2008, 158, 577-584.

12 J. C. Fanning, Coord. Chem. Rev., 2000, 199, 159-179.

13 S. J. Klippenstein, V. S. Pande and D. G. Truhlar, J. Am. Chem. Soc., 2014, 136, 528-546.

14 X. F. Wu, Y. L. Hu, F. Zhao, Z. Z. Huang and D. Lei, J. Environ. Sci., 2006, 18, 1167-1175.

15 Y. Yuasa, Jpn Kakai JP 197 196[87 197196] 31 Aug 1987.

16 H. Wilson, C. Carr and M. Hacke, Chem. Cent. J., 2012, 6, 113.

17 D. A. Nguyen, M. A. Iwaniw and H. S. Fogler, Chem. Eng. Sci., 2003, 58, 4351-4362.

18 W. R. L. van der Star, M. J. van de Graaf, B. Kartal, C. Picioreanu, M. S. M. Jetten and M. C. M. van Loosdrecht, Appl. Environ. Microbiol., 2008, 74, 4417-4426.

19 B. Kartal, W. J. Maalcke, N. M. de Almeida, I. Cirpus, J. Gloerich, W. Geerts, H. J. M. O. den Camp, H. R. Harhangi, E. M. Janssen-Megens, K. J. Francoijs, H. G. Stunnenberg, J. T. Keltjens, M. S. M. Jetten and M. Strous, Nature, 2011, 479, 127.

20 J. Mondal, K. T. Nguyen, A. Jana, K. Kurniawan, P. Borah, Y. L. Zhao and A. Bhaumik, Chem. Commun., 2014, 50, 12095-12097.

21 Z. M. Peng, M. Z. Wu, Y. Xiong, J. Wang and Q. W. Chen, Chem. Lett., 2005, 34, 636-637.

22 Y. P. He, Q. L. Sheng, B. Liu and J. B. Zheng, Electrochim. Acta, 2012, 66, 82-87.

23 Y. Liu, J. Zhou, J. Gong, W. P. Wu, N. Bao, Z. Q. Pan and H. Y. Gu, Electrochim. Acta, 2013, 111, 876-887.
24 O. Gutfleisch, M. A. Willard, E. Bruck, C. H. Chen, S. G. Sankar and J. P. Liu, Adv. Mater., 2011, 23, 821-842.

25 S. Rakshit, C. J. Matocha and G. R. Haszler, J. Environ. Qual., 2005, 34, 1286-1292.

26 A. T. Iffat, Z. T. Maqsood and N. Fatima, J. Chem. Soc. Pak., 2005, 27, 174-177.

27 T. K. Ross and R. A. Francis, Corros. Sci., 1978, 18, 351-361.

28 Q. L. Hongsen Zhang, J. Wang and J. Liu, RSC Adv., 2015, 5, 8.

29 F. Elkabbany, Y. Badr and M. Tosson, Phys. Status Solidi A, 1981, 63, 699-704.

30 A. Ritter and A. Peppas, J. Controlled Release, 1987, 37-42.

31 M. H. Mccrady, American Journal of Public Health and the Nations Health, 1966, 56, 684-685.

32 V. Vimonses, S. M. Lei, B. Jin, C. W. K. Chowd and C. Saint, Chem. Eng. J., 2009, 148, 354-364.

33 A. Ritter and R. Munoz-Carpena, J. Hydrol., 2013, 480, 33-45. 34 L. Wu, R. Munoz-Carpena, B. Gao, W. Yang and Y. A. Pachepsky, Environ. Sci. Technol., 2014, 48, 3883-3890. 35 J. A. Jaen, J. De Obaldia and M. V. Rodriguez, Hyperfine Interact., 2011, 202, 25-38.

36 R. Y. Liu and A. W. Xu, RSC Adv., 2014, 4, 40390-40395.

37 G. K. B. Lopes, H. M. Schulman and M. Hermes-Lima, Biochim. Biophys. Acta, Gen. Subj., 1999, 1472, 142-152.

38 A. H. Basaran and O. H. Tuovinen, Appl. Microbiol. Biotechnol., 1986, 24, 338-341.

39 X. M. Li, T. T. Shen, D. B. Wang, X. Yue, X. Liu, Q. Yang, J. B. Cao, W. Zheng and G. M. Zeng, J. Environ. Sci., 2012, 24, 269-275.

40 C. L. Mangun, M. A. Daley, R. D. Braatz and J. Economy, Carbon, 1998, 36, 123-129.

41 L. B. Kong, H. Li, J. Zhang, Y. C. Luo and L. Kang, Appl. Surf. Sci., 2010, 256, 6688-6693.

42 J. A. Jaen and C. Navarro, Hyperfine Interact., 2009, 192, 6167.

43 R. S. Peres, E. Cassel, C. A. Ferreira and D. S. Azambuja, Ind. Eng. Chem. Res., 2014, 53, 2706-2712.

44 Y. Zhang, Z. X. Zhang, T. B. Li, X. G. Liu and B. S. Xu, Spectrochim. Acta, Part A, 2008, 70, 1060-1064.

45 E. G. I. d. S. N. J. A. Jáen and C. Herńandez, Hyperfine Interact., 1999, 122, 8.

46 A. T. Iffat, Z. T. Maqsood, K. Ali and S. Nisar, J. Chem. Soc. Pak., 2004, 26, 151-156.

47 J. Iglesias, E. G. De Saldana and J. A. Jaen, Hyperfine Interact., 2001, 134, 109-114.

48 R. G. Andrade, J. S. Ginani, G. K. B. Lopes, F. Dutra, A. Alonso and M. Hermes-Lima, Biochimie, 2006, 88, 1287-1296. 